the probablility of superiority to $\mathrm{PBO}$ was $80 \%$ for $\mathrm{CBPI} \mathrm{PI}$ and $89 \%$ to $96 \%$ for secondary endpoints. LYB showed inconsistent separation from PBO across the endpoints, with probablilty of superiority to PBO $54 \%$ to $89 \%$. The separation of carprofen and PBO arms demonstrated assay sensitivity. The incidence of adverse events for LYA $(35.9 \%)$ was comparable to that of carprofen $(25.6 \%)$ and PBO (32.6\%). For LYB, the incidence was significantly higher versus PBO $(59.5 \%, P=.017)$.

\begin{tabular}{|c|c|c|c|c|}
\hline \multicolumn{5}{|c|}{$\begin{array}{l}\text { Mean CFB to Week } 2 \text { in primary and secondary efficacy endpoints and probability of } \\
\text { being superior to PBO }\end{array}$} \\
\hline & $\begin{array}{c}\text { LYA } \\
(n=39)\end{array}$ & $\begin{array}{c}\text { LYB } \\
(n=42)\end{array}$ & $\begin{array}{c}\text { Carprofen } \\
(n=39)\end{array}$ & $\begin{array}{c}\text { PBO } \\
(n=43)\end{array}$ \\
\hline $\begin{array}{l}\text { CBPI PI (Primary) } \\
\text { LS mean CFB }(95 \% \mathrm{CI}) \\
\text { Prob. superior to PBO, \% }\end{array}$ & $\begin{array}{c}-1.85 \\
(-2.44,-1.25) \\
80\end{array}$ & $\begin{array}{c}-1.54 \\
(-2.14,-0.95) \\
54\end{array}$ & $\begin{array}{c}-2.12 \\
(-2.73,-1.52) \\
93\end{array}$ & $\begin{array}{c}-1.50 \\
(-2.07,-0.92)\end{array}$ \\
\hline $\begin{array}{l}\text { CBPI PS } \\
\text { LS mean CFB ( } 95 \% \text { CI) } \\
\text { Prob. superior to PBO, } \%\end{array}$ & $\begin{array}{c}-1.66 \\
(-2.14,-1.18) \\
94\end{array}$ & $\begin{array}{c}-1.39 \\
(-1.87,-0.91) \\
78\end{array}$ & $\begin{array}{c}-1.56 \\
(-2.05,-1.08) \\
90\end{array}$ & $\begin{array}{c}-1.14 \\
(-1.60,-0.68)\end{array}$ \\
\hline $\begin{array}{l}\text { CBPI OI } \\
\text { LS mean CFB }(95 \% \mathrm{CI}) \\
\text { Prob. superior to PBO, } \%\end{array}$ & $\begin{array}{c}0.56 \\
(0.30,0.82) \\
89\end{array}$ & $\begin{array}{c}0.37 \\
(0.11,0.63) \\
56\end{array}$ & $\begin{array}{c}0.61 \\
(0.35,0.87) \\
93\end{array}$ & $\begin{array}{c}0.35 \\
(0.10,0.59)\end{array}$ \\
\hline $\begin{array}{l}\text { LOAD Mobility } \\
\text { LS mean CFB ( } 95 \% \mathrm{CI}) \\
\text { Prob. superior to PBO, } \%\end{array}$ & $\begin{array}{c}-6.18 \\
(-8.38,-3.97) \\
96\end{array}$ & $\begin{array}{c}-5.43 \\
(-7.61,-3.24) \\
89\end{array}$ & $\begin{array}{c}-7.52 \\
(-9.75,-5.28) \\
99\end{array}$ & $\begin{array}{c}-3.55 \\
(-5.68,-1.42)\end{array}$ \\
\hline
\end{tabular}

Conclusions: The study results support an efficacy proof-of-concept signal for the mPGES1 inhibitor mechanism for treatment of chronic OA pain in canine patients.

Acknowledgements: We also thank Leijun Hu, Alain Frix, and Claire Smith of Eli Lilly and Company for their contributions to the study.

Disclosure of Interest: C. Robertson-Plouch Shareholder of: Eli Lilly and Company, Employee of: Eli Lilly and Company, J. Stille Shareholder of: Eli Lilly and Company, Employee of: Eli Lilly and Company, P. Liu Shareholder of: Eli Lilly and Company, Employee of: Eli Lilly and Company, S. Malcolm Shareholder of: Eli Lilly and Company, Employee of: Eli Lilly and Company, D. Brown Grant/research support from: AlcheraBio, Centrexion Corporation, Enceladus, Integrated Chinese Medicine Holdings, and Regeneus, M. Warner Shareholder of: Eli Lilly and Company, Employee of: Eli Lilly and Company, M. Fisher Shareholder of: Eli Lilly and Company, Employee of: Eli Lilly and Company

DOI: 10.1136/annrheumdis-2017-eular.3113

\section{SAT0503 CAN BALNEOTHERAPY MODIFY MICRORNA EXPRESSION LEVELS IN OSTEOARTHRITIS? A COMPARATIVE STUDY IN PATIENTS WITH KNEE OSTEOARTHRITIS TREATED WITH MUD-BATH THERAPY}

C. Giannitti, A. De Palma, S. Cheleschi, J. Facciolo, N.A. Pascarelli, M. Galeazzi, A. Fioravanti. Department of Medicine, Surgery and Neurosciences.

Rheumatology Unit, Policlinico le Scotte, Siena, Italy

Background: MicroRNAs (miRNAs) are a class of 19-23 nucleotides long non-coding RNAs that post-transcriptionally regulate the activity of target mRNAs. MicroRNAs are involved in cartilage homeostasis and play an important role in the pathogenesis of osteoarthritis (OA). They have been detected in human plasma and in synovial fluid and are considered as potential diagnostic biomarkers and therapeutic targets of OA. Balneotherapy is a common non-pharmacological treatment for $O A$ patients. In a previous published prospective single-blind randomized clinical trial in patients with knee OA, we showed that a cycle of mud-bath therapy (MBT) in addition to conventional treatments induced an improvement on pain, functional capacity and quality of life in comparison to standard treatment alone. Objectives: as part of this study we evaluated the whole blood levels of miR-155, 223, 181a, 146a and miR-let-7e, which are involved in the pathogenesis of OA. Methods: Thirty-two patients aged between 50 and 75 years with knee OA defined by the ACR criteria were included for the current analysis, based on the availability of blood sample at basal time and after 2 weeks. Twenty-one patients (MBT group) were daily treated with a combination of daily local mud-packs at $42^{\circ} \mathrm{C}$ and baths in mineral water, at $37^{\circ} \mathrm{C}$ for $15 \mathrm{~min}$, for a total of 12 applications over a period of 2 weeks, in addition to standard therapy; the other eleven patients (control group) continued their conventional treatment alone.

Clinical parameters [global pain score by a 0-100 mm Visual Analog Scale (VAS); physical function, total pain score and total stiffness score (WOMAC)] and microRNAs expression were performed at basal time and after 2 weeks. Peripheral whole blood was collected into PAXgeneTM Blood RNA tubes and then stored a $-80^{\circ} \mathrm{C}$. Total RNA was extracted using the PAXgeneTM Blood miRNA kit and the relative expression of miR-146a, miR-155, miR-223, miR-181a and miR-let-7e were determined by qRT-PCR.

Results: At the end of MBT we observed a statistically significant improvement of clinical paramethers. Furthermore, we observed a significant decrease of miR-155, 181a and miR-146a $(p<0.001)$ and of miR-223 $(p<0.01)$ expression levels. On the contrary, no clinical and biochemical modifications were detected in the control group. Concerning miR-let-7e expression levels no significant variations were showed in both groups after 2 weeks.

Conclusions: Our data showed that MBT can modify the expression levels of miR-155, 181a, 146a and 223 expression levels, that are up-regulated in OA. This MBT effect could be explained considering the role of the heat stress and of the hydrostatic pressure, since some miRNAs were found to be temperature and mechano-responsive. Further studies are needed to better explain the mechanism of action of MBT and the role of miRNAs in OA.

References:

[1] Cheleschi S et al. Int J Mol Sci. 2017.

[2] De Palma A et al. Clin Exp Rheumatol. 2017

[3] Fioravanti A et al. Int J Biometeorol. 2015.

[4] Potla R. et al. RNA. 2015.

Disclosure of Interest: None declared

DOI: 10.1136/annrheumdis-2017-eular.6462

\section{SAT0504 PREDICTIVE ABILITY OF BIOMARKERS LINKED WITH SYNOVITIS FOR FUTURE INCIDENCE OF PAINFUL KNEE OSTEOARTHRITIS IN A COMMUNITY BASED COHORT OF MIDDLE-AGE WOMEN}

C.S. Thudium ${ }^{1}$, S. Kluzek ${ }^{2}$, J.L. Newton ${ }^{2}$, T. Spector ${ }^{3}$, D. Hart ${ }^{3}$, M.A. Karsdal ${ }^{1}$, A.C. Bay-Jensen ${ }^{1}$, N. Arden ${ }^{2}$. ${ }^{1}$ Biomarkers \& Research, Nordic Bioscience, Herlev, Denmark; ${ }^{2}$ Nuffield Department of Orthopaedics, Rheumatology and Musculoskeletal Sciences, University of Oxford, Oxford; ${ }^{3}$ Department of Twin Research, King's College London, St. Thomas Hospital, London, United Kingdom

Background: Radiographic knee osteoarthritis (RKOA) is associated with the knee pain. However, more than half of the middle-aged individuals with RKOA will report no concurrent knee pain. Specific matrix metalloproteinases (MMPs) generated protein fragments have been associated with knee synovitis and suggested as specific neo-epitope biomarkers of joint remodelling

Objectives: The aim of the study was to evaluate the association between MMP-derived neo-epitope biomarkers measured in serum, and future incidence of either painful RKOA or RKOA without pain, in a cohort of middle-aged women with no RKOA at baseline.

Methods: 585 participants (mean age 53.2, mean BMI 25.1) from the Chingford 1000 Women Study Chingford Women Study had serum biomarker levels of MMP- degraded of CRP (CRPM), collagen type II (C2M) and collagen type III (C3M) measured at year 2 or 3 of the study. All participants had a Kellgren Lawrence $(\mathrm{KL})$ score of 0 in both knees at baseline. Ten years following the recruitment, incidence of $\mathrm{RKOA}$ was determined as $\mathrm{KL}>2$ and painful RKOA was defined as the presence of pain on any number of days in the preceding month in the knee with RKOA. Log-transformed normalised biomarker levels were utilised in separate logistic regression models adjusted for age. Outcomes were defined as either RKOA without pain or painful RKOA. Further analyses were performed adjusting for both age and BMI.

Results: $24.6 \%$ of women developed RKOA during 10 years after the recruitment, but only $8.9 \%$ of developed RKOA associated with concurrent knee pain. After adjusting for age, statistically significant positive associations were found between C3M and CRPM and the risk of developing painful RKOA with odds ratio (OR) $=3.4(95 \%$ confidence interval $(\mathrm{Cl}): 1.4$ to 8.2$)$, and $\mathrm{OR}=2.5(95 \% \mathrm{Cl}: 1.2,5.2)$ respectively. After adjusting for age and $\mathrm{BMI}$, only $\mathrm{C} 3 \mathrm{M}$ was positively associated with risk of developing painful RKOA with OR=3.2 (95\% CI: 1.3, 7.8).

Conclusions: In a population of middle-aged women without knee osteoarthritis, an MMP generated neo-epitope of collagen III previously linked with knee synovitis (C3M) can independently identify high-risk individuals for developing painful RKOA. These findings indicate that targeting MMP activity may be a promising therapeutic strategy in well-targeted populations.

Disclosure of Interest: C. Thudium Employee of: Nordic Bioscience, S. Kluzek: None declared, J. Newton: None declared, T. Spector: None declared, D. Hart: None declared, M. Karsdal: None declared, A. Bay-Jensen: None declared, N. Arden: None declared

DOI: 10.1136/annrheumdis-2017-eular.5761

\section{SAT0505 SELF-REPORTED KNEE INSTABILITY ASSOCIATED WITH PAIN AND ACTIVITY LIMITATIONS PRIOR AND ONE YEAR AFTER TOTAL KNEE ARTHROPLASTY IN PATIENTS WITH KNEE OSTEOARTHRITIS}

C. Leichtenberg $^{1}$, J.J. Meesters ${ }^{1}$, J. Dekker ${ }^{2,3}$, R.G. Nelissen ${ }^{1}$, T.P. Vliet Vlieland ${ }^{1}$, M. van der Esch ${ }^{4}$. ${ }^{1}$ Orthopedics, Leiden University Medical Center, Leiden; ${ }^{2}$ Rehabilitation Medicine; ${ }^{3}$ Psychiatry, VU University Medical Center; ${ }^{4}$ Rehabilitation Research, Reade, Amsterdam, Netherlands

Background: Sixty to $80 \%$ of the patients with knee osteoarthritis (OA) reported self-reported knee joint instability, which was associated with pain and activity limitations. One previous randomized control trial described the prevalence of retained self-reported knee joint instability after total knee arthroplasty (TKA) (32\%). To better understand self-reported knee joint instability in usual care there is a need to replicate and extend the results.

Objectives: The aims of the study were to determine (i) the prevalence of self-reported knee instability prior and one year after TKA, (ii) the associations between self-reported knee instability, pain, activity limitations and quality of life prior and one year after TKA, (iii) the course of self-reported knee instability over time and (iv) the associations between retained knee instability, pain, activity limitations and quality of life. 